\title{
The determinants of housework time
}

\section{Boosting the efficiency of household production could have large economic effects}

Keywords: housework, gender, home production, tax policy, outsourcing

\section{ELEVATOR PITCH}

The time household members in industrialized countries spend on housework and shopping is substantial, amounting to about half as much as is spent on paid employment. Women bear the brunt of this burden, driven in part by the gender wage differential. Efforts to reduce the gender wage gap and alter gendered norms of behavior should reduce the gender bias in household production time and reduce inefficiency in home production. Policymakers should also note the impact of tax policy on housework time and its market substitutes, and consider ways to reduce the distortions caused by sales and income taxes.

\section{KEY FINDINGS}

\section{Pros}

๑ Household production yields valuable services and constitutes an important sector of the economy.

- Gender differences in housework time that are caused by gender differences in opportunity costs or productivity are efficient.

๑ Some observed differences in housework time could be attributable to preferences; the limited evidence available on preferences suggests that, on average, women prefer housework more than men do.

(- Evidence suggests that the time spent on home production has decreased while reliance on market substitutes has increased.

๑ Gender differences in housework time have been declining and may be contributing to reduced gender differentials in earnings.
Housework time constitutes about $50 \%$ of time spent on employment and education in most countries

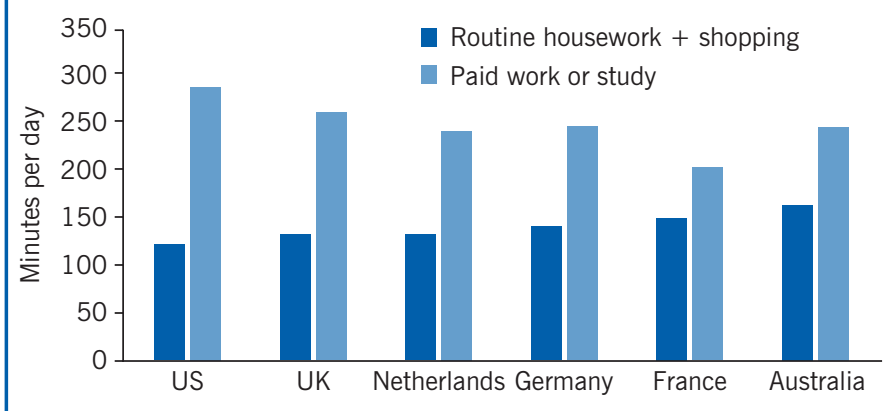

Source: Based on Figure 1

\section{Cons}

- Contributions in the household sector are often undervalued, leading to underestimates of economic well-being.

- Gender differences in housework time caused by social norms or discrimination are not efficient.

- Income taxes distort incentives and lead individuals, especially women, to allocate more time than is socially optimal to household production.

- Women who spend more time on housework have been found to earn lower wages, suggesting a vicious cycle, with wage differentials driving allocations to housework time and vice versa.

- The value households place on market purchased versus home produced goods is uncertain, but sales taxes likely distort households' choices.

\section{AUTHOR'S MAIN MESSAGE}

Substantial resources are devoted to household production, and boosting efficiency in this sector could have large economic effects. A number of policies could support this effort. Sales and income taxes motivate people to spend time on housework that would be better spent on other activities. Basing tax rates on individual rather than household earnings would reduce such incentives, particularly for women entering couple households. Policies to reduce labor market discrimination and discourage gendered norms of behavior would further enhance efficiency, but any gender differences in housework time that reflect different preferences or abilities are appropriate. 


\section{MOTIVATION}

The focus in this article is on routine household tasks that every individual performs, such as cleaning, laundry, meal preparation, home maintenance and repair, and shopping. Time spent on care activities for children and adults, in and outside of the household, is not addressed here. While caregiving is a very important use of time, research indicates that the determinants of caregiving differ substantially from those for routine housework and so caregiving deserves separate analysis.

Household members spend considerable time on routine household tasks even in industrialized countries. Figure 1 compares the average time prime-aged individuals spend on housework and the time spent on employment and education in 28 mostly developed countries [1]. The time devoted to housework exceeds $50 \%$ of the time spent on employment and education in 16 of these countries and exceeds $40 \%$ in all but three. Average time spent on housework ranges from a low of 89 minutes a week in South Korea to a high of 203 minutes a week in Mexico.

Figure 1 . Time use by country, 2003-2017

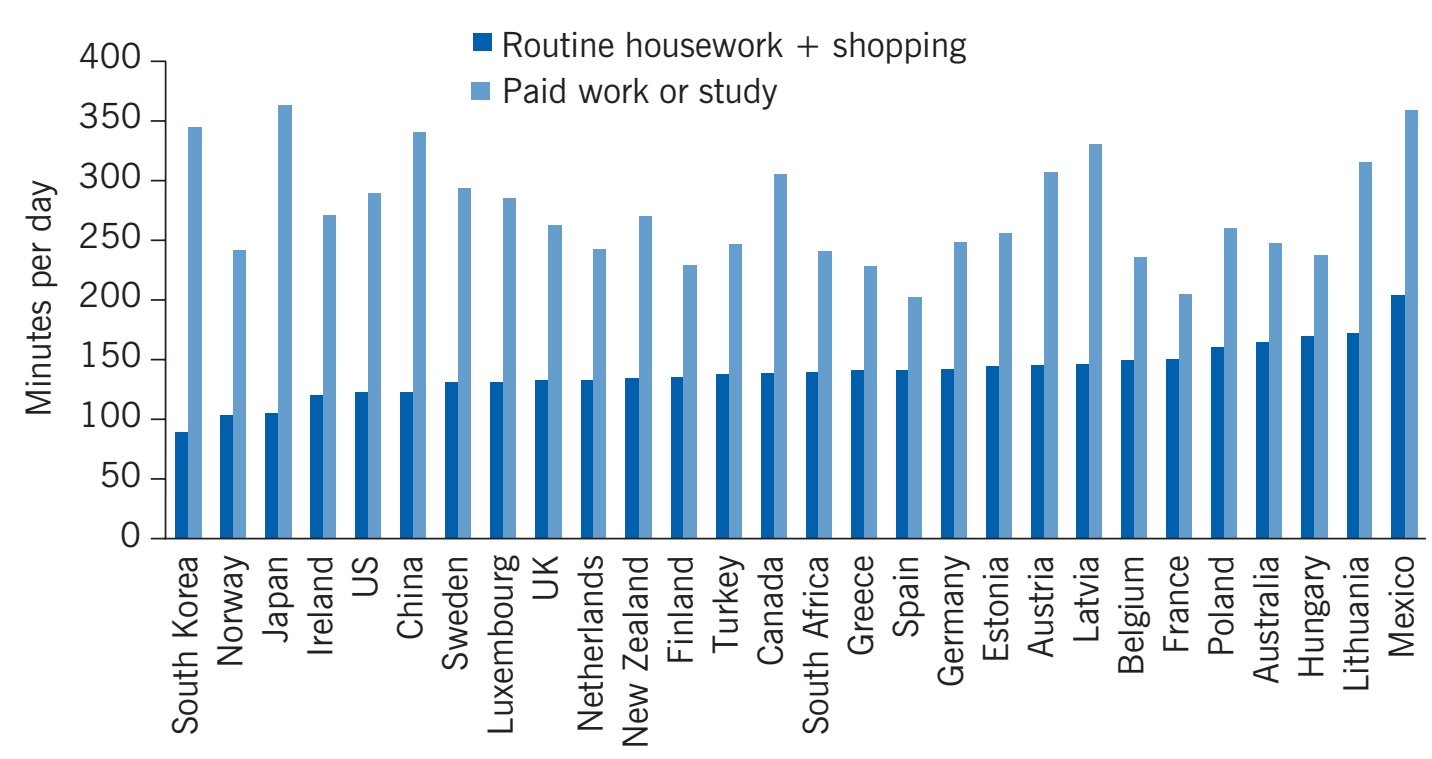

Note: Most data capture persons aged 15-64. Australian data modified to include only persons aged 25-64.

Source: Author's own based on OECD data. Online at: https://stats.oecd.org/Index.aspx?datasetcode=TIME_USE [Accessed August 23, 2019].

Standard economic measures of well-being such as national gross domestic product (GDP) exclude the value of household production. No one disputes that housework produces valuable products, like clean clothes, well maintained homes, and healthful meals, which contribute to individual health and well-being. The difficulty lies in valuing these contributions. If this time were valued as highly as labor income, incorporating the value of household time in GDP would increase GDP by roughly the same proportion as the time differential between housework and employment, or $50 \%$. More careful estimates vary with the methodology employed to value time but are also typically large. An OECD estimate for 2011 suggests that including unpaid housework would boost OECD average GDP by about 33\% [1]. The value of unpaid housework in the UK in 2016 
was estimated by the Office for National Statistics in the Household Satellite Account, UK 2015 and 2016, to be about 39\% of GDP. Improving inefficient resource allocation in this sector could have substantial ramifications throughout the economy.

\section{DISCUSSION OF PROS AND CONS}

\section{Household production as a whole: Theory}

Households decide what resources to devote to household production at the same time as they decide on their goods consumption, their participation in the labor market, and their leisure activities. As is the case for business firms, this resource demand is a function of desired output, available technology, and resource prices.

Demand for household output is not readily observable but can be said to logically vary with household characteristics. Larger households have more clothes to wash, more people to feed, and typically more living space to clean. Thus, larger households demand more household production. Wealthier households on average have larger homes that require more time to clean. Of course, different households have different preferences and different standards of cleanliness that introduce differential demands for housework.

On the supply side, both relative resource prices and available production methods influence the resources used to produce household goods in the home. These resources include household members' labor, raw materials, and capital equipment. Food and basic cleaning supplies are necessary no matter what production technology is adopted. The same household goods can, however, be produced using different production methods. Clothes and dishes can be washed by hand or using machines. Household appliances economize on household time, but at a price. Wealthier households are better able to afford that price, but relative resource prices are also critical. Earnings or potential earnings are commonly used to proxy for time costs. Higher income households have a higher opportunity cost of time and will find it more advantageous to substitute capital for labor in household production.

Similarly, just as firms experience economies of scale in production, so will households. Both will choose the production technologies that allow them to produce at the lowest possible cost. Appliances come in different sizes to address different household needs, but costs are rarely proportional to size. While there is twice as much space to vacuum in a house that is twice as large as another, the time to set up for and clean up after is relatively fixed. It takes twice as much food to produce a meal for two as a meal for one, but not nearly twice as much time. In general, while larger households will spend more time on housework than smaller households, household production is not best characterized by a constant returns to scale production function (in which outputs are directly proportional to inputs).

Finally, household goods can be purchased in the market: maids clean, handypersons do repairs, gardeners provide lawn services, laundromats wash clothes, restaurants, and even grocers, sell ready-to-eat meals. Data indicate that fewer than $10 \%$ of couple households hire maids, but many outsource meal preparation. Over $90 \%$ of couples responding to the UK Family Expenditure Survey of 2000-2001 reported having purchased ready-made meals or dined out in the previous two weeks. In the US, expenditures on meals away from home have risen from 25\% of food expenditures in 1954 to $39 \%$ in 1980 to over $50 \%$ in 2018. The more rapid increase in the price of food away from home as compared with the price of food eaten at home explains less than half of this increase. The relative quality 
of these substitutes for home production is not clear, but households have certainly voted for some of these services with their purses.

A policy-relevant concern is that different resources used in household production are taxed at different rates. Sales taxes raise the cost of resources and services purchased in the market and, all else being equal, households facing higher sales taxes will use more labor and fewer goods and services in the production of household goods than is socially optimal. Such taxes are often lower for goods used in home production than for goods purchased ready-made. Income taxes will further distort this choice, causing households to adopt even more laborintensive home production techniques. Progressive taxes aggravate the disincentives for higher income households. That some services, such as those provided by maids, handypersons, and gardeners, are provided in the black market moderates this bias, but at a cost.

\section{Household production as a whole: Evidence}

Many of the factors driving household production discussed above are difficult to measure: preferences, economies of scale, and capital equipment amongst them. The importance of labor resource costs can be demonstrated empirically in several ways using earnings potential. First, people aged 65 and older participate less in the labor market than people aged 15-64, and are generally believed to have a lower opportunity cost of time. Not inconsequentially, people in the older age group contribute $40 \%$ more time to routine housework than people aged 15-64 in the US and one-half as much more in Australia. Second, research indicates that time spent on housework is countercyclical, with people who are unemployed reporting more time on housework on average than people who are employed. Research suggests that time spent on home production may absorb $30 \%$ of forgone market work hours [2]. Third, people spend more time on housework on weekends than on weekdays, when most people face greater employment opportunities and so a greater opportunity cost of time. In Italy, the differential is $11 \%$; in Australia it is $18 \%$; and in the US it is about $30 \%$. Decisions regarding household resource use and production method thus appear heavily dependent on relative resource prices.

Not surprisingly, market purchases of household goods are quite sensitive to earnings as well as prices. The share of expenditures on food away from home relative to all food ranged from $34.9 \%$ for households earning less than $\$ 15,000$ to $51.2 \%$ for households earning more than $\$ 200,000$ according to the 2018 US Consumer Expenditure Survey. Likewise, the demand for service providers including maids and laundry services varies substantially with household income [3]. The importance of marginal prices was illustrated when France implemented policies to reduce the tax burden associated with hiring maids and encouraged people to officially declare their use of domestic workers. The result was a particularly large increase in reported domestic service employment [4].

\section{Intra-household time allocation: Theory}

The discussion so far has focused on household resource use. But households are made up of individuals, and the time allocated to housework varies substantially across individuals. The most notable differences are by gender. On average, women in OECD countries contribute $69 \%$ of routine housework time. This share is $61 \%$ in the US, $65 \%$ in Australia, and $77 \%$ in Italy. Both economists and sociologists have sought to explain these gender differences in intra-household time allocation. 
Two economic theories of household decision-making yield similar predictions [5]. Both assume time spent on housework is a necessary evil. One, the bargaining model of household decision-making, posits that people retain their individual utility functions (modified to incorporate the utility of others in their household) when forming joint households and bargain either cooperatively or non-cooperatively to maximize utility. The relative bargaining power of the individuals in the household is an important predictor of the time allocation. Each individual's bargaining power is a function of that individual's expected utility should the household break apart. This utility is a function of an individual's opportunities in the marriage/couples' market, and his/her earnings ability and assets. The better an individual's outside opportunities, the greater that person's bargaining power and the less time the individual is likely to spend on housework.

The second theory, the collective model of household decision-making, expresses household utility as a weighted sum of the utility of the individuals within the household. The weights are modeled as relative power functions. Thus, the individual with the most power has the most say in determining how resources and time are allocated within the household. Power is modeled as a function of the relative resources an individual contributes to the household, much like the bargaining literature models the bargaining power.

Both theories suggest that the partner with the greater earnings will spend relatively less time on housework, all else being equal, highlighting the importance of earnings and the gender wage differential in determining housework time. Both theories also acknowledge that differential productivity in household production and differential preferences for household-produced goods could be determining factors.

Sociologists also have a long history of work in this field [6]. Some sociological theories that explain why women spend more time on housework than men are closely related to economic theories: relative resources or power theory, for example, suggests that the partner with the most resources in the household will spend less time on housework. Sociologists, however, also emphasize the importance of ideology and beliefs. Gender role ideology and preferences regarding egalitarianism have been explored in this context. Theory predicts that households with more egalitarian preferences and less gendered norms of behavior will allocate household tasks more equally, all else being equal.

Sociologists also theorize that the division of household tasks may be a nonlinear function of relative earnings power-specifically, that women's relative earnings and share of housework will be negatively related so long as women earn less than their partner but positively related when women earn more than their partner. Women in this case spend more time doing housework (or men less) in order to demonstrate that they are still women (or men). This behavior is known as "doing gender." To the extent that beliefs and ideology influence household time allocation, economic efficiency declines. Policy prescriptions that counter gendered notions of behavior will increase the economic efficiency of time allocations. The most effective policy may be education interventions to provide boys and girls with gender-neutral role models and common household production skills.

\section{Intra-household gender differences: Evidence}

Attempts to validate these theories empirically have had varied success. That women on average are paid less than men suggests that women will find time spent on household production less costly than do men. Indeed, the correlation between the gender wage gap 
and women's share of unpaid work time across a set of 23 OECD countries is 0.43 , meaning the larger the gender gap in earnings, the larger the gender gap in unpaid work time [1]. That earnings are negatively related to housework time for women is well documented [5]. Results for men suggest little relation, which is perhaps not surprising given that men's labor supply varies little with earnings. However, on average, women spend more time on housework than their partners even when their earnings are comparable, indicating that earnings differentials alone cannot explain the entire gender difference in housework time. Little evidence exists on gender differences in productivity, but it seems unlikely that productivity differences in such simple tasks as cleaning, laundry, or dishwashing would be substantial.

Furthermore, tax policy may aggravate gender differences in time allocation. As stated earlier, income taxes are likely to cause households to allocate more time to household production and less time to market production than would be socially optimal. Research finds that single women, but not single men, increase their housework time when marginal tax rates rise [7]. Given observed gender differences in earnings, these results suggest that progressive tax rates based on household rather than individual income will have a disproportionate impact on women forming joint households with men, increasing women's propensity to allocate time to housework. Taxes based on individual rather than household earnings will distort incentives less [8].

Evidence also supports other theoretical predictions regarding household time allocation. Sociologists have documented evidence of "doing gender" in Australia and the US, though not in Sweden, where more egalitarian attitudes may diminish the impact of gender norms [6]. Indeed, it is in Scandinavian countries that women contribute the smallest share of housework. Other evidence suggests that social norms regarding the intra-household allocation of housework are well understood within households and influence relationship satisfaction [9]. In sum, evidence indicates that the gender difference in reported housework time is related to differences in opportunity cost, in relative power within the household, and in ideological preferences and social norms regarding the role of men and women in society.

Explaining gender differences in housework time becomes particularly important if individuals who expend more time and energy on housework have less time and energy for market employment and as a result earn lower wages. A substantial literature documents such a negative relation, particularly for women. The evidence is especially strong for the US, but has been reported using data for Australia, Canada, Denmark, and the UK. Results for Germany are mixed [10]. Such a feedback loop is of substantial concern as it is likely to perpetuate gender differences in both earnings and housework time.

\section{Changes over time}

If housework time is inversely proportional to earnings power, the time devoted to housework should have decreased over time as real wages rose. Technological advances in household production (the introduction of the washing machine, the microwave, and so on) should also have reduced the time devoted to housework. The data illustrate such a trend [11]. Average time spent on routine housework has declined by $17 \%$ over the last 50 years, from 22.1 hours a week to 18.3 hours for people aged 21-65 in the US. The decrease is particularly marked for women (from 32.9 hours a week to 22.6), whose real wages have increased more than those of men. Men have modestly increased their housework time (from 9.7 hours a week to 13.4). International evidence 
is limited, but some evidence for Australia between 1992 and 2006 and the UK between 2000 and 2014 indicates a similar trend toward gender equalization in housework time. In addition, perhaps in part to compensate for substantial decreases in household time (on the order of $10 \%$ ), there is evidence from the UK that use of maid services has increased substantially between 2000 and 2014, from about $6 \%$ to about $8 \%$ of households.

\section{Differentiating among housework tasks}

The discussion above assumes that housework constitutes a single task, which is certainly not the case. The routine housework discussed here includes meal preparation and cleanup, laundry and house cleaning, lawn and pet care, maintenance and repair activities, and shopping and other services. While an individual's opportunity cost per unit of time in terms of forgone earnings will be similar across tasks, some tasks require more skill than others-meal preparation and maintenance/repair activities in particular. On average, social norms would suggest that women acquire more food-related skills and men more repair-related skills.

Gender differences by task are well documented. Figure 2 illustrates the average minutes per week that men and women spend on five different housework tasks [1]. Women on average spend substantially more time than men on food preparation, cleaning, and shopping and substantially less time on maintenance and repair activities. Gender differences are less pronounced for lawn and pet care.

Figure 2. Housework time by gender and household type

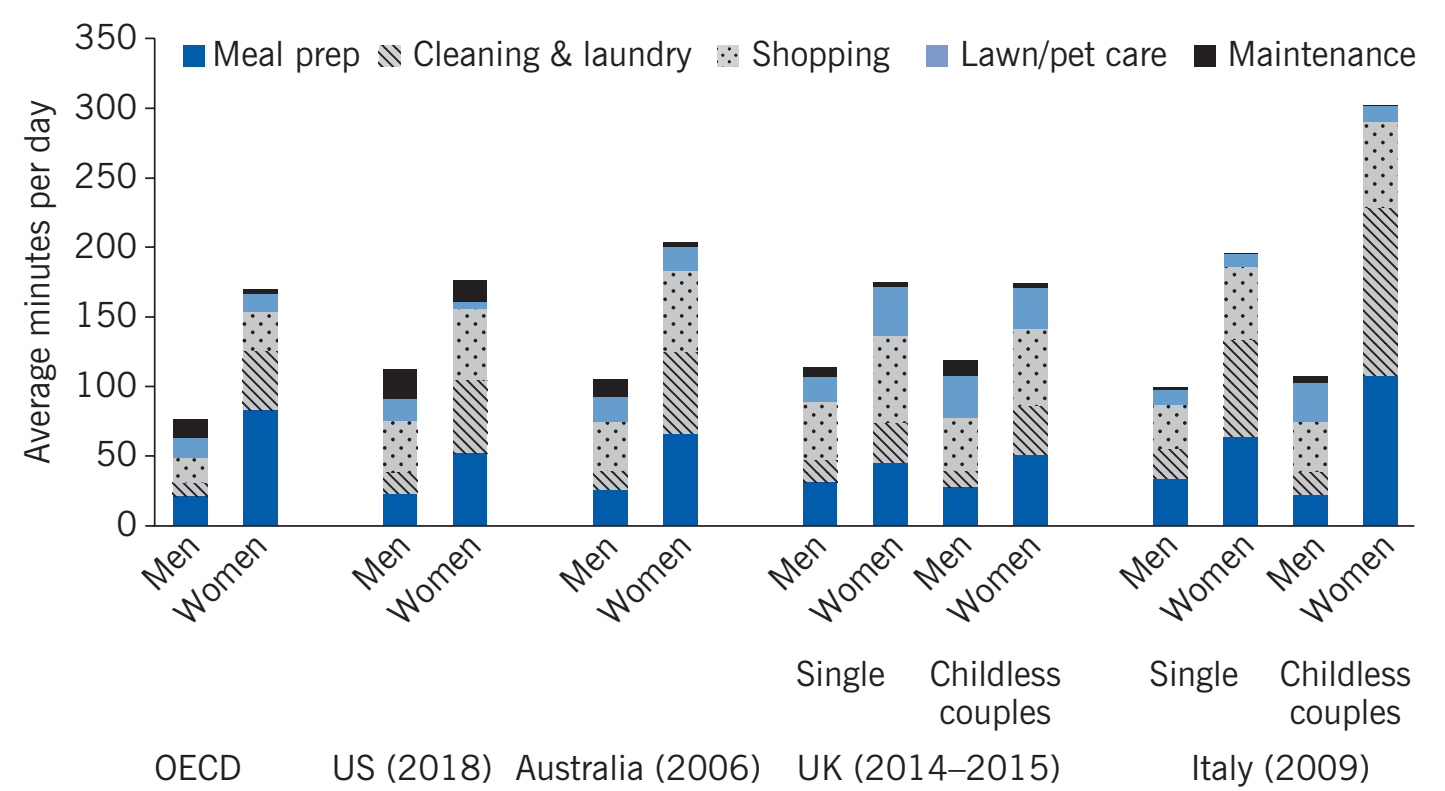

Note: OECD data reflect persons aged 15-64, US data persons aged 25-64, Australian data persons aged 15-64, Italian and UK data persons aged 25-60.

Source: OECD. "Cooking and caring, building and repairing: Unpaid work around the world." In: OECD (ed.). Society at a Glance 2011: OECD Social Indicators. Paris: OECD Publishing, 2011; pp. 9-27; American Time Use Survey (https://www.bls.gov/webapps/legacy/tusa_1tab1.htm); Australian Time Use Survey (https://www.abs.gov.au/ausstats/ abs@.nsf/mf/4153.0); and author's calculations from UK Time Use Survey 2014/15 and Italian Time Use Survey 2009. 
These figures do not control for household type. Single people are unable to specialize but must complete all necessary household tasks no matter their skill. In multi-person households, individuals can specialize to take advantage of skill differentials, to save on the fixed costs associated with set up, and to benefit from learning by doing. Thus, it is of some interest to compare household time use by task between single and multi-person households. Figure 2 shows that for Italy and the UK, the within-country distribution of time spent by task is similar for single-person and childless couple households. The gender difference is much greater for couples in Italy. Cross-country differences are more pronounced: Italian households devote more time to meal preparation and cleaning, but less to lawn/pet care and maintenance than their counterparts in the UK.

In both countries there is some evidence of specialization by task in couple households. Married women spend more time and married men less time on average on meal preparation and cleaning than their single counterparts. Married men in the UK, on the other hand, spend a little more time and married women a little less on average on lawn/ pet care and maintenance. Time spent shopping declines for both partners in couple households in the UK. By contrast, in Italy married people on average report more time than single people of the same gender for shopping, lawn/pet care, and maintenance, perhaps because of greater differences in residential characteristics.

Though Figure 2 provides evidence consistent with specialization, sample averages are not necessarily indicative of household-level allocations. On average, women may contribute $70 \%$ of the household time spent on an activity when in fact there is complete specialization within households. Such would be the case if the same time were spent in all households, but in $70 \%$ of the households women performed the activity being measured and in $30 \%$ of the households men performed the activity being measured. Evidence from Danish and US couple households confirms that specialization is greater at the household level than indicated by averages alone [12]. Figure 2 could also reflect different preferences, as these data reflect how individuals in different types of households spend their time, not how individuals change their time use following marriage.

\section{Preferences and time use}

Preferences for goods produced in the home and for the activities themselves will affect time allocations. People who place a higher value on home-produced goods will naturally devote more resources to their production-including more time. Those who enjoy the activities themselves will optimally invest more time. Much of the research in this area assumes that no one enjoys housework or housework time.

Data on preferences are limited and typically are activity- rather than outcome-based. Not surprisingly, evidence (from the US and UK) indicates that on average cooking, shopping, and gardening-hobbies for some people-are preferred to more mundane tasks like washing dishes, setting the table, and cleaning the house [13]. Yet other evidence (from the UK using both 2000 and 2014 data) indicates that preferences vary, both by gender and by household type. Women are more likely than men to report enjoying cleaning, gardening, and even laundry and ironing. Men are somewhat more likely to report enjoying repair work. Thus, differences in preferences could explain some of the gender difference in reported time. Men in couple households are more likely than single men to report enjoying repair work, while single women are more likely than women in couple households to 
report enjoying repair work. Single men are more likely than their coupled counterparts to report enjoying shopping and laundry. Single women report enjoying cleaning more often than women in couple households, but few other patterns stand out by household type for women. Whether preferences change with marriage or whether people who marry have different preferences than those who are single is not clear, but some of these differences could also support observed differences in intra-household time use.

In the one study that incorporates individual-specific preferences in an analysis of couples' housework time, the evidence suggests that men's preferences matter more than women's [14]. The more men reported enjoying housework tasks, the more time they spent and the less time their partner spent on housework. Women's preferences had no significant impact on the time allocated to housework. That any preferences were significantly associated with housework in this analysis is noteworthy because only house cleaning, laundry, ironing, and food shopping activities were analyzed. The study also suggests that household members are substitutes on weekdays and complements on weekends. The positive correlation between his and her housework time on weekends could be evidence that partners share common preferences or that couples engaged in home production produce more than just housework; they may be investing in their relationship by spending time together. In sum, despite the typical assumption that no one enjoys housework activities, preferences do appear to play a role.

\section{LIMITATIONS AND GAPS}

While the literature on home production is substantial, it is lacking in several respects. First, there has been little analysis of the nature of the home production function. Whether economies of scale are important, how valuable experience is, the extent to which capital goods substitute for labor, even whether there are fixed time costs associated with production that might influence the timing of as well as time spent on such activities-these are all relatively unexplored research questions whose study could advance understanding of the demand for housework time. Second, information is lacking on decision-making in multi-person households. Theories abound, but there is no consensus on the appropriate way to model this decision-making. A more accurate model would shed light not only on household time allocations but also on household consumption decisions. Third, although evidence suggests that preferences constitute an important determinant of individual time use, data on preferences are rarely available. If reported differences in housework time are due primarily to different preferences, policy actions are unnecessary. Only data on preferences can address this key question. Finally, information on the use of market alternatives for home production is limited and the degree to which these goods are substitutes is unknown.

\section{SUMMARY AND POLICY ADVICE}

The time spent on home production constitutes a significant resource that is not recognized in national accounts and is likely greater than is socially optimal given its exceptional position as an untaxed input. Marked gender differences in household time use exist. Gender differences in earnings play an important role, and that role is of some concern given the evidence that the time women spend on housework is quite sensitive to intra-household earnings differences and that women's wages are negatively affected by time spent on housework. 
Designing tax policies that focus on individual rather than household income would reduce women's tax-distorted incentive to increase their home production time once they are married. Policy designed to reduce the gender wage gap could also reduce the gender gap in housework time. However, the gender wage gap alone cannot explain the entire gender difference in housework time. Some of the difference has been attributed to differences in social norms; some may be attributable to differences in relative productivity and preferences. Preferences are for individuals to determine, not policymakers. However, education programs that provide both boys and girls with the skills necessary to maintain a home and that discourage gendered notions of behavior could increase the efficiency of time allocation decisions. There is evidence that the overall time spent on home production and gender differences in housework time are decreasing, mostly because women now spend less time on home production. Some evidence suggests that market substitutes for home production are becoming more important, even though such substitutes are typically taxed at a higher rate and so likely underutilized. Whether these changes are for the better depends on how one values home production and its alternatives.

\section{Acknowledgments}

The author thanks an anonymous referee and the IZA World of Labor editors for many helpful suggestions on earlier drafts. Previous work of the author contains a larger number of background references for the material presented here and has been used intensively in all major parts of this article [3], [5], [12], [13], [14]. Version 2 of the article includes a new "Pro" and a new "Con," as well as a further discussion of market-based alternatives. The text has been reorganized, the figures updated, and a new "Key reference" [9] added.

\section{Competing interests}

The IZA World of Labor project is committed to the IZA Code of Conduct. The author declares to have observed the principles outlined in the code.

(c) Leslie S. Stratton 


\section{REFERENCES}

\section{Further reading}

Burda, M., D. S. Hamermesh, and P. Weil. "Total work and gender: Facts and possible explanations." Journal of Population Economics 26:1 (2013): 239-261.

Hersch, J., and L. S. Stratton. "Housework, fixed effects, and wages of married workers." Journal of Human Resources 32:2 (1997): 285-307.

\section{Key references}

[1] OECD. "Cooking and caring, building and repairing: Unpaid work around the world." Society at a Glance 2011: OECD Social Indicators. Paris: OECD Publishing, 2011.

[2] Aguiar, M., E. Hurst, and L. Karabarbounis. "Time use during the Great Recession." American Economic Review 103:5 (2013): 1664-1696.

[3] Stancanelli, E. G. F., and L. S. Stratton. "Maids, appliances, and couples' housework: The demand for inputs to domestic production." Economica 81:323 (2014): 445-467.

[4] Flipo, A., D. Fougère, and L. Olier. "Is the household demand for in-home services sensitive to tax reductions? The French case." Journal of Public Economics 91:1-2 (2007): 365-385.

[5] Datta Gupta, N., and L. S. Stratton. "Examining the impact of alternative power measures on individual time use in American and Danish couple households." Review of Economics of the Household 8:3 (2010): 325-343.

[6] Evertsson, M., and M. Nermo. "Dependence within families and the division of labor: Comparing Sweden and the United States." Journal of Marriage and Family 66:5 (2004): 1272-1286.

[7] Gelber, A. M., and J. W. Mitchell. "Taxes and time allocation: Evidence from single women and men." Review of Economic Studies 79:3 (2012): 863-897.

[8] Kabátek, J., A. van Soest, and E. Stancanelli. "Income taxation, labour supply and housework: A discrete choice model for French couples." Labour Economics 27 (2014): 30-43.

[9] Foster, G., and L. S. Stratton. "What women want (their men to do): Housework and satisfaction in Australian households." Feminist Economics 25:3 (2019): 23-47.

[10] Hirsch, B., and T. Konietzko. "The effect of housework on wages in Germany: No impact at all." Journal for Labour Market Research 46:2 (2013): 103-118.

[11] Aguiar, M., and E. Hurst. "Measuring trends in leisure: The allocation of time over five decades." Quarterly Journal of Economics 122:3 (2007): 969-1006.

[12] Bonke, J., M. Deding, M. Lausten, L. S. Stratton. "Intrahousehold specialization in housework in the United States and Denmark." Social Science Quarterly 89:4 (2008): 1023-1043.

[13] Krueger, A. B. "Are we having more fun yet? Categorizing and evaluating changes in time allocation." Brookings Papers on Economic Activity 2007:2 (2007): 193-215.

[14] Stratton, L. S. "The role of preferences and opportunity costs in determining the time allocated to housework." American Economic Review102:3 (2012): 606-611.

\section{Online extras}

The full reference list for this article is available from:

https://wol.iza.org/articles/determinants-of-housework-time

View the evidence map for this article:

https://wol.iza.org/articles/determinants-of-housework-time/map 